\title{
Approach to dizziness in the emergency department
}

\author{
lleok Jung, Ji-Soo Kim
}

Department of Neurology, Seoul National University Bundang Hospital, Seoul National University College of Medicine, Seongnam, Korea

Acute dizziness/vertigo is among the most common causes for visiting the emergency department. The traditional approach to dizziness starts with categorizing dizziness into four types: vertigo, presyncope, disequilibrium, and nonspecific dizziness. However, a recently proposed approach begins with classifying dizziness/vertigo as acute prolonged spontaneous dizziness/vertigo, recurrent spontaneous dizziness/vertigo, recurrent positional vertigo, or chronic persistent dizziness and imbalance. Vestibular neuritis and stroke are key disorders causing acute prolonged spontaneous dizziness/vertigo, but the diagnosis of isolated vascular vertigo has increased by virtue of developments in clinical neurotology and neuroimaging. However, a well-organized bedside examination appears more sensitive than brain imaging in diagnosing strokes presenting with acute dizziness/vertigo. A detailed history is vital to diagnose recurrent spontaneous dizziness/vertigo since confirmatory diagnostic tests are usually unavailable. Isolated positional vertigo is usually caused by benign paroxysmal positional vertigo, which can be treated at the bedside. In recent years, marked progress has occurred in the evaluation/management of acute dizziness/vertigo. However, even with developments in imaging technology, the diagnosis of acute dizziness/vertigo largely relies on bedside examination.

Keywords Dizziness; Vertigo; Stroke; Benign paroxysmal positional vertigo; Emergency service, hospital

\footnotetext{
Capsule

Summary

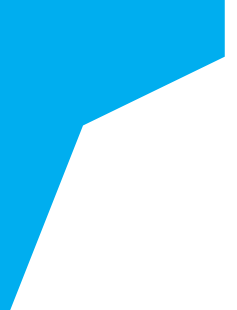

What is already known

Acute dizziness/vertigo is among the most common causes for visiting the emergency department.

What is new in the current study

A recently proposed approach to dizziness/vertigo begins with classifying those as acute prolonged spontaneous dizziness/vertigo, recurrent spontaneous dizziness/vertigo, recurrent positional vertigo, or chronic persistent dizziness and imbalance. Even with developments in imaging technology, the diagnosis of acute dizziness/vertigo largely relies on bedside examination.
}

elSSN: 2383-4625

Received: 19 March 2015

Revised: 21 April 2015

Accepted: 21 April 2015

Correspondence to: Ji-Soo Kim Department of Neurology, Seoul National University Bundang Hospital, Seoul National University College of Medicine, 82 Gumi-ro, 173beon-gil, Bundang-gu, Seongnam 463-707, Korea

E-mail: jisookim@snu.ac.kr

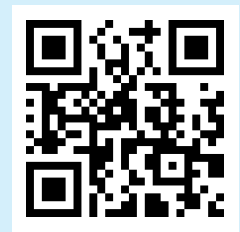

How to cite this article:

Jung I, Kim JS. Approach to dizziness in the emergency department. Clin Exp Emerg Med 2015;2(2):75-88.

This is an Open Access article distributed under the terms of the Creative Commons Attribution Non-Commercial License (http:// creativecommons.org/licenses/by-nc/3.0/). 


\section{INTRODUCTION}

Acute dizziness is among the most common causes for visiting the emergency department (ED). ${ }^{1}$ However, the differential diagnosis of dizziness is challenging for several reasons. First of all, dizziness can be a manifestation of conditions varying from lifethreatening disorders to normal physiologic responses. Second, no diagnostic confirmatory tool is available for most disorders causing dizziness. Thus, the diagnosis is largely based on a constellation of clinical features obtained with careful history taking and bedside examinations. ${ }^{2}$ Neither blood tests nor brain imaging are cost-effective when applied to dizzy patients without discrimination. ${ }^{3}$ Third, the term "dizziness" may represent various feelings including vertigo, lightheadedness, pre-syncope, unsteadiness, and just not feeling well. ${ }^{4}$ The traditional approach to dizziness starts with defining the type of dizziness based on the belief that each type of dizziness reflects a specific underlying cause: vertigo is vestibular, presyncope is cardiovascular, disequilibrium is neurologic, and nonspecific dizziness is psychiatric or metabolic. ${ }^{4}$ However, some patients have difficulty describing their specific type of dizziness. ${ }^{5}$ Furthermore, vestibular disorders may present with various patterns of dizziness and cardiac disorders/systemic hypotension can give rise to vertigo along with vestibular signs. ${ }^{6}$ Thus, the traditional approach of relying heavily on the "quality of the symptom" faces challenges. ${ }^{3}$ A more recently proposed approach to dizziness begins with classifying the type of dizziness/vertigo into acute prolonged spontaneous dizziness/vertigo, recurrent spontaneous dizziness/vertigo, recurrent positional vertigo, or chronic persistent dizziness and imbalance (Table 1). This new approach is considered more practical and more helpful in organizing a differential diagnosis in each category.

In this review, we will focus on the diagnosis and management of acute spontaneous and recurrent positional vertigo, which are the most common types of dizziness/vertigo presenting in the ED.

Table 1. Presentation of different dizziness types and differential diagnosis

\begin{tabular}{|c|c|}
\hline Types & Main differential diagnosis \\
\hline $\begin{array}{l}\text { Acute prolonged spontaneous } \\
\text { dizziness/vertigo }\end{array}$ & $\begin{array}{l}\text { Vestibular neuritis/labyrinthitis } \\
\text { Stroke }\end{array}$ \\
\hline $\begin{array}{l}\text { Recurrent spontaneous dizziness/ } \\
\text { vertigo }\end{array}$ & $\begin{array}{l}\text { Meniere's disease } \\
\text { Vestibular migraine } \\
\text { Psychogenic dizziness } \\
\text { Vertebrobasilar transient ischemic attack }\end{array}$ \\
\hline Recurrent positional vertigo & Benign paroxysmal positional vertigo \\
\hline Chronic dizziness and imbalance & $\begin{array}{l}\text { Degenerative brain disorders } \\
\text { Bilateral vestibulopathy } \\
\text { Psychogenic dizziness }\end{array}$ \\
\hline
\end{tabular}

\section{ACUTE SPONTANEOUS DIZZINESS/VERTIGO}

Patients in this category develop acute dizziness/vertigo without triggering factors. ${ }^{2}$ The dizziness/vertigo mostly accompanies autonomic symptoms, such as nausea/vomiting and unsteadiness. The attack may be transient ( $<24$ hours) or prolonged. Vestibular neuritis, a benign inflammatory disorder involving the vestibular labyrinth, and stroke are the key disorders for differential diagnosis in this presentation type.

In contrast to the traditional belief that dizziness/vertigo usually accompanies other neurological signs/symptoms in cerebrovascular disorders, isolated vascular vertigo is increasingly identified by virtue of recent developments in clinical neurotology and neuroimaging. ${ }^{7}$ Indeed, dizziness/vertigo and imbalance are the most common symptoms in vertebrobasilar ischemia, which comprises up to $20 \%$ of all ischemic strokes. ${ }^{8,9}$ Recent prospective studies using a large database reported dizziness as a presenting symptom in $47 \%$ to $75 \%$ of patients with posterior circulation strokes. ${ }^{10,11}$ It is important to differentiate isolated vascular vertigo from more benign disorders involving the inner ear since the therapeutic strategy and prognosis differ between these conditions. ${ }^{12}$ Misdiagnosis of acute strokes may result in significant morbidity and mortality, while over diagnosis of vascular vertigo can lead to costly work-ups and medication. ${ }^{12}$ The introduction of diffusion-weighted magnetic resonance imaging (MRI) has greatly enhanced the infarction detection in patients with vascular dizziness/vertigo, especially due to impaired posterior circulation. ${ }^{13}$ However, well-organized bedside neurotologic evaluation is more sensitive than MRI in detecting acute infarction as a cause of spontaneous vertigo of $>24$ hours, especially during the first 48 hours. ${ }^{14-16}$

\section{History taking}

Even though neurotological examination plays a vital role in the differential diagnosis of acute spontaneous prolonged dizziness/ vertigo, history taking should include preceding infections, vascular risk factors (such as hypertension, diabetes, dyslipidemia, smoking, and cardiac disease), and associated headache or neck pain. Even without other signs suggestive of a central pathology, acute dizziness/vertigo associated with unprecedented severe headache or neck pain strongly indicates a cerebrovascular disorder. ${ }^{17}$

Patients visiting the ED with dizziness/vertigo have a two-fold (95\% confidence interval $[\mathrm{Cl}], 1.35$ to $2.96 ; \mathrm{P}<0.001$ ) higher risk for strokes/cardiovascular events than those without dizziness/ vertigo in a 3 -year follow-up study..$^{18}$ Furthermore, patients with vertigo and three or more vascular risk factors have a 5.51-fold higher risk for strokes $(95 \% \mathrm{Cl}, 3.10$ to $9.79 ; \mathrm{P}<0.001)$ than those 
without risk factors. ${ }^{18}$ Other studies adopting the $A B C D^{2}$ score, ${ }^{19}$ a clinical prediction tool to assess the risk of strokes after a transient ischemic attack, found a cerebrovascular event only in 1.0\% of ED patients with dizziness and a score of three or less compared to $8.1 \%$ in patients with a score of four or more. ${ }^{20}$ Of note, $27 \%$ of patients with a score of six or seven suffered from cerebrovascular episodes. ${ }^{20}$ Thus, the $A B C D^{2}$ score may predict cerebrovascular attacks in patients with transient vertigo.

\section{Evaluation}

\section{Nystagmus}

Patterns of spontaneous nystagmus, when present, are most informative in evaluating patients with acute dizziness/vertigo. ${ }^{21}$ For proper evaluation of spontaneous nystagmus, one should observe the direction and the effect of gaze on the intensity and direction of the nystagmus. In vestibular neuritis, spontaneous nystagmus is torsional-horizontal beating away from the lesion side (Fig. 1). ${ }^{22}$ The nystagmus typically increases during gaze in the direction of the spontaneous nystagmus and decreases during gaze
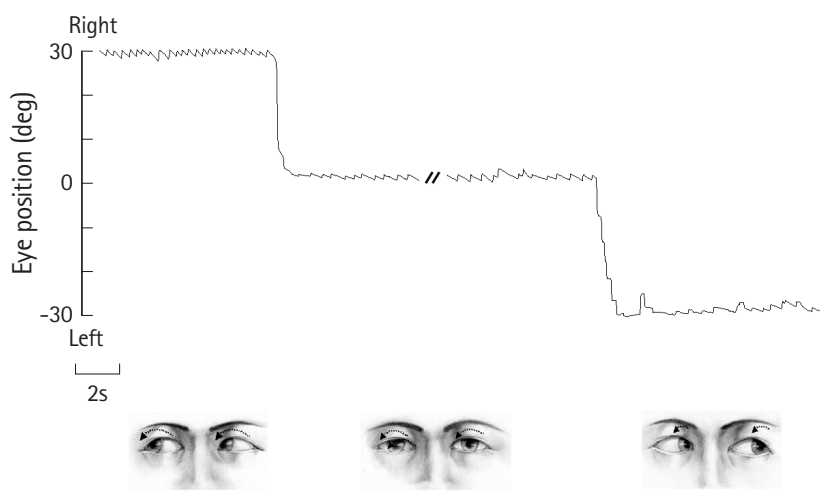

Fig. 1. Nystagmus in left peripheral vestibulopathy. In unilateral vestibular neuritis, mixed torsional-horizontal nystagmus beats to the intact side. Nystagmus typically increases during gaze in the direction of nystagmus and decreases during gaze in the opposite direction (Alexander's law), but never changes directions.
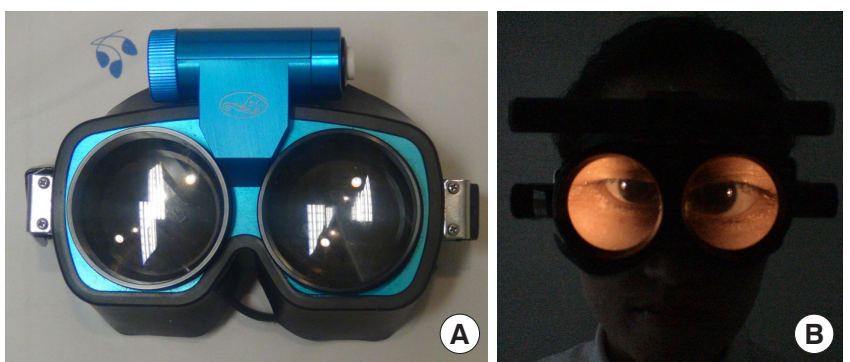

Fig. 2. Frenzel glasses. Frenzel glasses remove visual fixation by adopting 20-diopter convex lenses $(A)$ and facilitate detection of nystagmus by magnifying the eyes (B). in the opposite direction (Alexander's law, Fig. 1). ${ }^{23}$ Since peripheral vestibular nystagmus is markedly suppressed by visual fixation, proper observation of nystagmus requires the removal of visual fixation using Frenzel glasses (Fig. 2) ${ }^{24}$ In contrast, the direction and fixation effect may be variable in central vestibular nystagmus. Accordingly, when the characteristics of nystagmus do not conform to those of peripheral vestibular nystagmus, it should be considered central. ${ }^{25-28}$ However, even unidirectional horizontal-torsional nystagmus suppressed by visual fixation should not be simply regarded as peripheral unless other findings, such as positive head impulse test (HIT) or caloric paresis, are supportive of peripheral vestibular lesions. The distinguishing features of peripheral and central nystagmus are summarized in Table 2.

Various bedside maneuvers can induce nystagmus or modulate pre-existing spontaneous nystagmus. Even in patients with spontaneous nystagmus, pattern modulation may reveal the underlying pathology or aid in diagnosis. In patients with compensated vestibulopathy, induction of nystagmus by various maneuvers is crucial in revealing the underlying vestibular imbalance. ${ }^{29,30}$ Gazeevoked nystagmus (GEN) refers to nystagmus that develops when patients take eccentric eye positions. As GEN is caused by impaired gaze-holding in those positions, which causes centripetal drift of the eyes, GEN beats in the direction of gaze. ${ }^{31,32}$ GEN is one of the most sensitive ocular motor signs for central pathologies in the patients with acute vestibular syndrome. ${ }^{13,14}$ Headshaking nystagmus (HSN) can be induced using either passive (by examiner) or active (by patients) head oscillation. The patient's head is pitched forward by about $30^{\circ}$ to bring the horizontal semicircular canals into the plane of stimulation. The head is then shaken horizontally in a sinusoidal fashion at a rate of about 2 to $3 \mathrm{~Hz}$ with an amplitude of $20^{\circ}$ for 15 seconds. ${ }^{33}$ In unilateral peripheral vestibulopathy, HSN initially beats to the intact side, decays over 20 seconds, and then goes through a weak reversal. ${ }^{34}$ In contrast, HSN patterns may vary in central vestibular disorders. In general, central patterns of HSN include unusually strong HSN elicited by weak head-shaking, intense HSN in patients without

Table 2. Differentiation between peripheral and central nystagmus

\begin{tabular}{|c|c|c|}
\hline Characteristics & Peripheral & Central \\
\hline Direction & $\begin{array}{l}\text { Mixed torsional- } \\
\text { horizontal }\end{array}$ & $\begin{array}{l}\text { Varies: pure vertical, torsional, } \\
\text { or horizontal } \\
\text { Mixed }\end{array}$ \\
\hline Change of direction & $\begin{array}{l}\text { Unidirectional: } \\
\text { contralesional }\end{array}$ & $\begin{array}{l}\text { Varies: unidirectional or } \\
\text { direction changing }\end{array}$ \\
\hline Effect of fixation & Suppression & $\begin{array}{l}\text { Varies: increased, decreased, } \\
\text { or no effect }\end{array}$ \\
\hline Adaptation & Within days & Often persists \\
\hline Other neurologic deficits & No & Often \\
\hline
\end{tabular}


caloric paresis, ipsilesional HSN, HSN in the opposite direction of spontaneous nystagmus, and perverted HSN (i.e., vertical or torsional nystagmus developing in response to horizontal head-shaking). .3,35-37 $^{3}$

HIT

HIT is the most effective method for detecting loss of vestibular function at the bedside. ${ }^{38}$ For HIT, the examiner asks the patient to fixate on a target in front of the eyes and briskly turns the patient's head horizontally. The head impulse should be unpredictable with a low amplitude $\left(10^{\circ}\right.$ to $\left.20^{\circ}\right)$ and high acceleration $\left(2,000^{\circ} /\right.$ $s^{2}$ to $4,000^{\circ} / s^{2}$ ) of head rotation. ${ }^{39}$ If the vestibulo-ocular reflex is working normally, HIT will generate a compensatory eye movement in the opposite direction of the head rotation with equal amplitude, holding the gaze steady. In contrast, HIT toward the side of a peripheral vestibular lesion will give rise to a re-fixation catch-up saccade at the end of head motion to bring the image of the target back to the fovea. This corrective saccade (overt saccade) indicates a decreased vestibulo-ocular reflex in patients with peripheral vestibular deficits (Fig. 3). While an overt saccade is observed in most patients with acute peripheral vestibular disorders, HIT is usually normal in central vestibular lesions. ${ }^{40}$ Thus, one should suspect a central pathology if a patient with acute vertigo and spontaneous nystagmus exhibits normal HIT. ${ }^{13}$ A refixation saccade in a different plane (i.e., vertical catch-up saccade after horizontal rotation) also suggests a central lesion. ${ }^{41-43}$ However, bedside HIT may be negative when the vestibular deficits are partial ${ }^{44}$ or the covert saccades complement the vestibular deficits. ${ }^{39}$

\section{Ocular misalignment}

Ocular misalignment occurs frequently in central vestibulopathies, and should be determined in nine cardinal gaze positions along with limitations in the range of eye movements. Skew deviation refers to vertical ocular misalignment resulting from vestibular tone imbalance. ${ }^{45}$ The presence of skew deviation may be inferred by vertical diplopia and can be confirmed with the cover test. With one eye covered, a corrective vertical movement of the opposite eye to fixate on a target indicates the presence of skew deviation. Skew deviation may occur in any acute lesion involving the posterior fossa, but the majority of cases are seen in association with brainstem stroke. ${ }^{46}$ Skew deviation is typically observed as a component of the ocular tilt reaction (OTR) that includes head tilt, ocular torsion, and skew deviation (Fig. 4). As a rule, the head is tilted toward the side of the lower eye and the ocular torsion occurs in the same direction with the upper poles of the eyes rotating toward the lower eye. ${ }^{47}$ Lesions below the lower pons cause ipsiversive OTR, while more rostral lesions induce contraversive OTR.

\section{Balance}

The severity of imbalance and falling direction may provide important clues for underlying vestibular impairments. In general, patients with unilateral peripheral vestibular loss, such as vestibular neuritis, can maintain balance even when the dizziness/vertigo is very severe. ${ }^{17}$ In contrast, severe imbalance that impairs sitting or standing usually indicates a central pathology. ${ }^{17}$

\section{Brain imaging}

The use of neuroimaging studies is increasing for ED patients with dizziness. Nevertheless, the sensitivity of computed tomography

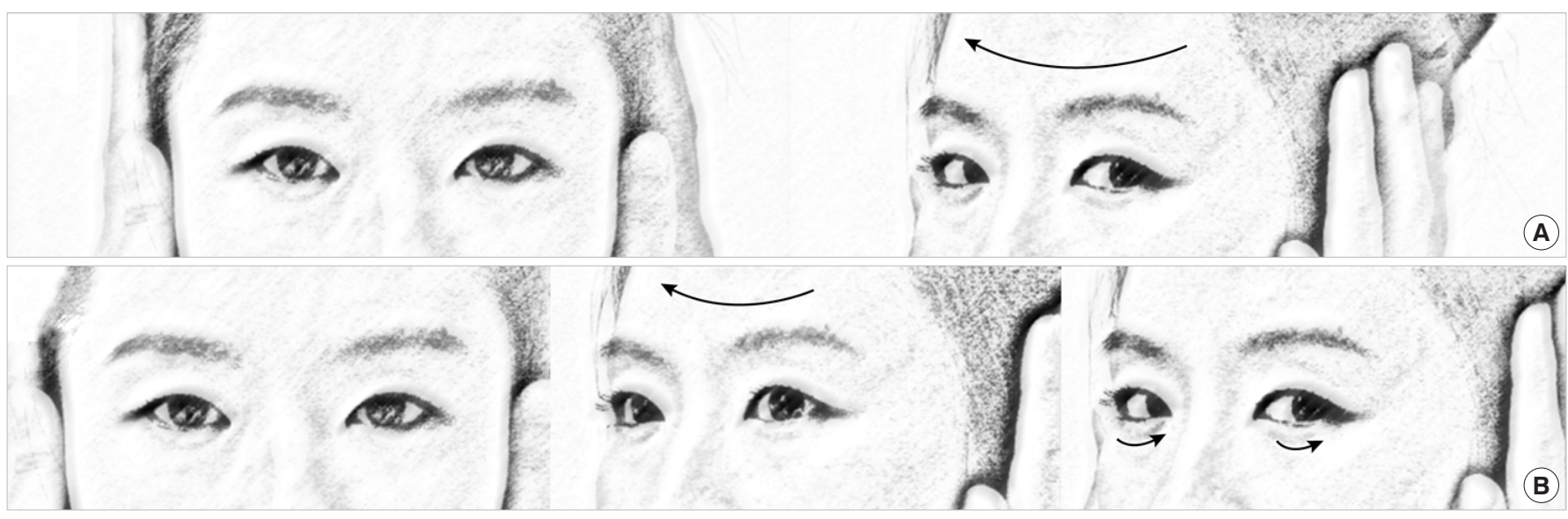

Fig. 3. Head impulse test (HIT). (A) In healthy subjects, HIT (arrow) normally induces a rapid compensatory eye movement in the opposite direction, and steady fixation is attained. (B) In patients with unilateral peripheral vestibular hypofunction, HIT toward the affected side (large arrow) produces a corrective saccade (small arrows) after head rotation because the eyes move with the head due to a defective vestibulo-ocular reflex, thus losing the target with head rotation. 

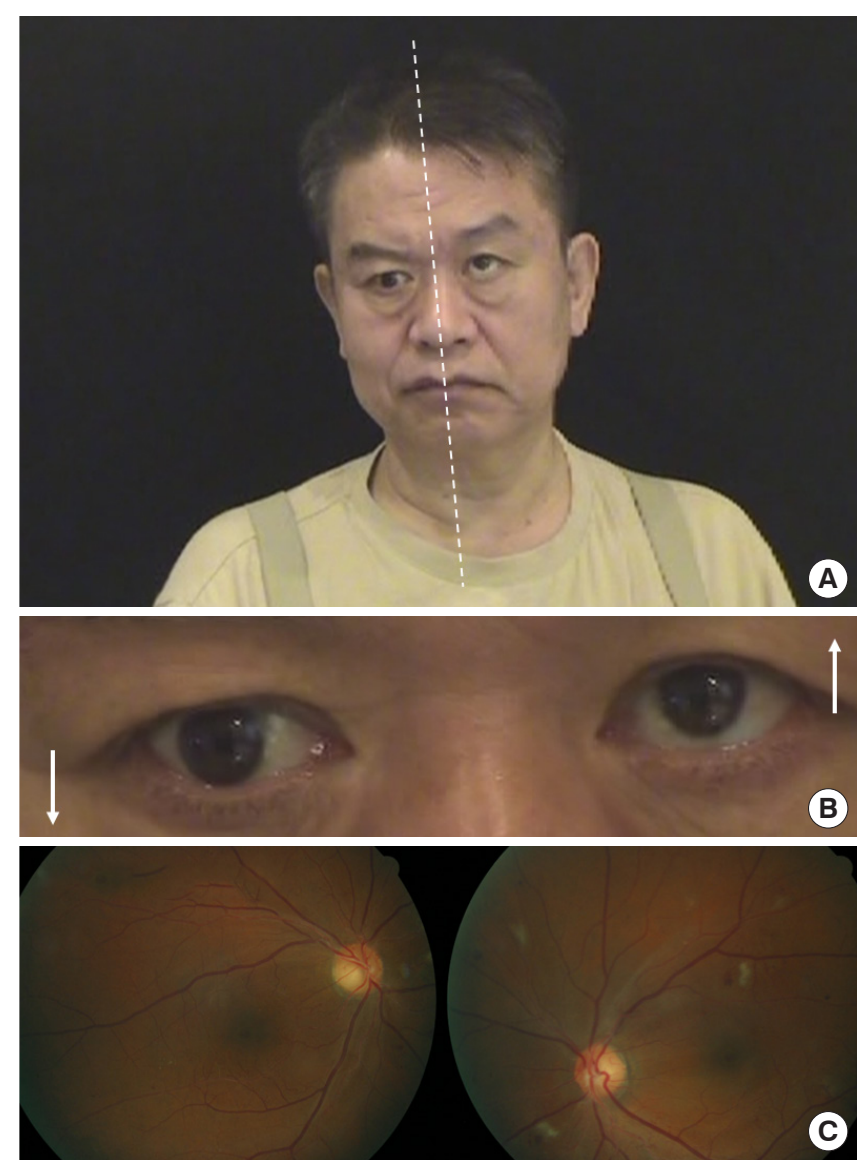

Fig. 4. Ocular tilt reaction. The ocular tilt reaction refers to $(A)$ head tilt, (B) skew deviation, and (C) ocular torsion ascribed to imbalance in the otolithic inputs from the utricles on both sides. The head tilt and ocular torsion occur toward the hypotropic eye. Informed consent was received from the patient.

scans to identify strokes in the acute setting is disappointing (26\%). ${ }^{48}$ Thus, a negative computed tomography does not exclude the probability of stroke. MRI is much more sensitive, but the sensitivity is lowest within 24 hours of onset, especially in lesions involving the brainstem or cerebellum. ${ }^{40,48,49}$ Thus, serial evaluation is required to confirm a stroke because initial diffusion-weighted MRI may be false negative in 12\% to 20\% of stroke patients within the first 48 hours. ${ }^{14,50}$ Additionally, MRI cannot detect isolated labyrinthine infarctions that may progress to involve portions of the brainstem and cerebellum supplied by the anterior inferior cerebellar artery (AICA). ${ }^{51}$ Perfusion imaging may help determine the presence and extent of hypoperfusion, especially when routine MRI, including diffusion-weighted images, are normal. ${ }^{52} \mathrm{How}-$ ever, the exact role of perfusion imaging needs to be validated in isolated vertigo of vascular origin.

\section{Optimal testing}

Recent studies have shown well-organized bedside examination is superior to brain imaging in detecting strokes in a subgroup of patients with acute spontaneous dizziness/vertigo. This includes HINTS, which stands for Head-Impulse-Nystagmus-Test-of-Skew. ${ }^{14}$ In a previous study, the presence of negative HIT, direction-changing nystagmus, or skew deviation predicted stroke with 100\% sensitivity and 96\% specificity in patients with acute vertigo and at least one vascular risk factor after excluding those with a history of recurrent vertigo. In contrast, initial diffusion-weighted MRI was false negative in $12 \%$ of these patients, especially within 48 hours of symptom onset. ${ }^{29}$ However, HINTS may not be sufficiently robust to detect infarctions involving the AICA territory since HIT is mostly positive due to concurrent labyrinthine infarction. ${ }^{15,53,54}$ Indeed, HINTS failed to detect central lesions in five of 18 patients with AICA infarctions. ${ }^{53}$ Therefore, detection of central lesions may require additional testing, such as horizontal head shaking ${ }^{53}$ or hearing evaluation (HINTS plus). ${ }^{15,16}$

\section{Transient vascular vertigo and isolated labyrinthine infarction}

Despite being a common finding in vertebrobasilar ischemia, diagnosis of isolated transient dizziness/vertigo of a vascular origin remains a challenge. ${ }^{9,55,56}$ Transient isolated vascular vertigo typically occurs abruptly and usually lasts several minutes. ${ }^{57}$ According to a report, $62 \%$ of patients with vertigo due to vertebrobasilar ischemia had a history of at least one isolated episode of vertigo, and 19\% developed vertigo as the initial symptom. ${ }^{55}$ Patients with AICA territory infarctions may have isolated recurrent vertigo, fluctuating hearing loss, and/or tinnitus (similar to Meniere's disease) as initial symptoms 1 to 10 days prior to permanent infarction..$^{58}$

This diagnostic difficulty also applies to isolated labyrinthine infarctions since no confirmatory tool other than a pathologic study is currently available for this condition. ${ }^{59}$ As the internal auditory artery, usually an AICA branch, supplies the inner ear, vertebrobasilar ischemic strokes may present with vertigo and hearing loss due to labyrinthine infarction. As isolated labyrinthine damage may precede ponto-cerebellar involvement from an AICA infarction, audiovestibular loss may serve as an indicator of progression into more widespread infarction involving the posterior circulation, mainly in the AICA territory..$^{51,60}$ Labyrinthine infarction should be considered in older patients with acute vertigo and unilateral hearing loss, particularly when there is a history of strokes or known vascular risk factors. Because labyrinthine infarctions are not well visualized with current imaging techniques, ${ }^{59}$ clinicians should consider all the clinical features and laboratory findings available when attempting to determine the cause of acute vertigo and hearing loss. ${ }^{61}$ 


\section{Management}

Patients with suspected episodes of vascular vertigo should have a prompt assessment of their cerebral vasculature. ${ }^{12,62}$ As non-lacunar mechanisms are more common (47\%) than previously thought in acute vestibular syndrome from small infarctions, more aggressive therapies may be indicated to prevent stroke recurrences in vascular vertigo. ${ }^{16,63}$

The treatment of vestibular neuritis generally includes supportive care during the acute phase, steroids, and vestibular rehabilitation. ${ }^{64}$ Symptomatic care with vestibular suppressants should be used only during the first several days when patients suffer from severe nausea/vomiting and vertigo, as such medications may delay central compensation. ${ }^{23}$ The efficacy of corticosteroids is controversial. A recent Cochrane review concluded there is currently insufficient evidence to support the use of corticosteroids in patients with idiopathic acute vestibular dysfunction. ${ }^{65} \mathrm{Admin}-$ istration of valcyclovir alone, or in combination with glucocorticoids, showed no effect. ${ }^{66}$ In contrast, vestibular rehabilitation hastens recovery. ${ }^{67}$

\section{RECURRENT POSITIONAL VERTIGO}

According to the Barany Society classification of vestibular symptoms ${ }^{68}$ positional vertigo is defined as vertigo triggered by and occurring after a change of head position in space relative to gravity. Thus, positional vertigo should be differentiated from headmotion vertigo, which occurs only during head motion, or orthostatic vertigo, which is triggered by and occurs upon rising. ${ }^{68}$ Isolated positional vertigo is usually caused by benign paroxysmal positional vertigo (BPPV). ${ }^{69}$ BPPV is characterized by brief spinning sensations, usually lasting less than 1 minute. ${ }^{69}$ Vertigo typically develops when a patient gets in or out of bed, rolls over in bed, tilts the head back, or bends forward. ${ }^{69}$ BPPV is explained by otoconia dislodged from the macula of the utricular otolith entering the semicircular canals. ${ }^{70}$ When there is a change in the

Table 3. Diagnosis and treatment of benign paroxysmal positional vertigo involving each semicircular canal

\begin{tabular}{llll}
\hline \multirow{2}{*}{ Type } & \multicolumn{2}{c}{ Diagnosis } & \multirow{2}{*}{ Treatment } \\
\cline { 2 - 3 } & Maneuver & Induced nystagmus & \\
\hline PC & $\begin{array}{l}\text { Dix-Hallpike } \\
\text { Side-lying }\end{array}$ & $\begin{array}{c}\text { Upbeat \& ipsiversive } \\
\text { torsional }\end{array}$ & $\begin{array}{l}\text { Epley maneuver } \\
\text { Semont maneuver }\end{array}$ \\
HC-geotropic & Supine roll & Geotropic & $\begin{array}{l}\text { Barbecue maneuver } \\
\text { Gufoni maneuver }\end{array}$ \\
& & & $\begin{array}{l}\text { Gufoni maneuver } \\
\text { HC-apogeotropic }\end{array}$ \\
& Supine roll & Apogeotropic & Head-shaking maneuver
\end{tabular}

$\mathrm{PC}$, posterior canal; $\mathrm{HC}$, horizontal canal.

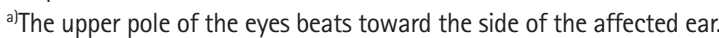

position of the head with respect to gravity, otolithic debris moves to a new position within the semicircular canals, leading to a false sense of rotation. ${ }^{70}$ BPPV usually arises from the posterior semicircular canal (PC-BPPV), which accounts for $60 \%$ to $90 \%$ of all cases. ${ }^{69}$ However, the proportion of patients with BPPV involving the horizontal semicircular canal (HC-BPPV) may have been underestimated since HC-BPPV is more likely to remit spontaneously than PC-BPPV. ${ }^{71}$ BPPV rarely involves the anterior semicircular canal, probably because of its uppermost position where otolithic debris is unlikely to become trapped. ${ }^{72}$

BPPV is usually idiopathic with a peak age of onset between 50 and 60 years and a female-to-male ratio of 2:1 to $3: 1 .^{73}$ Recent studies reported an association of BPPV with osteopenia/os-
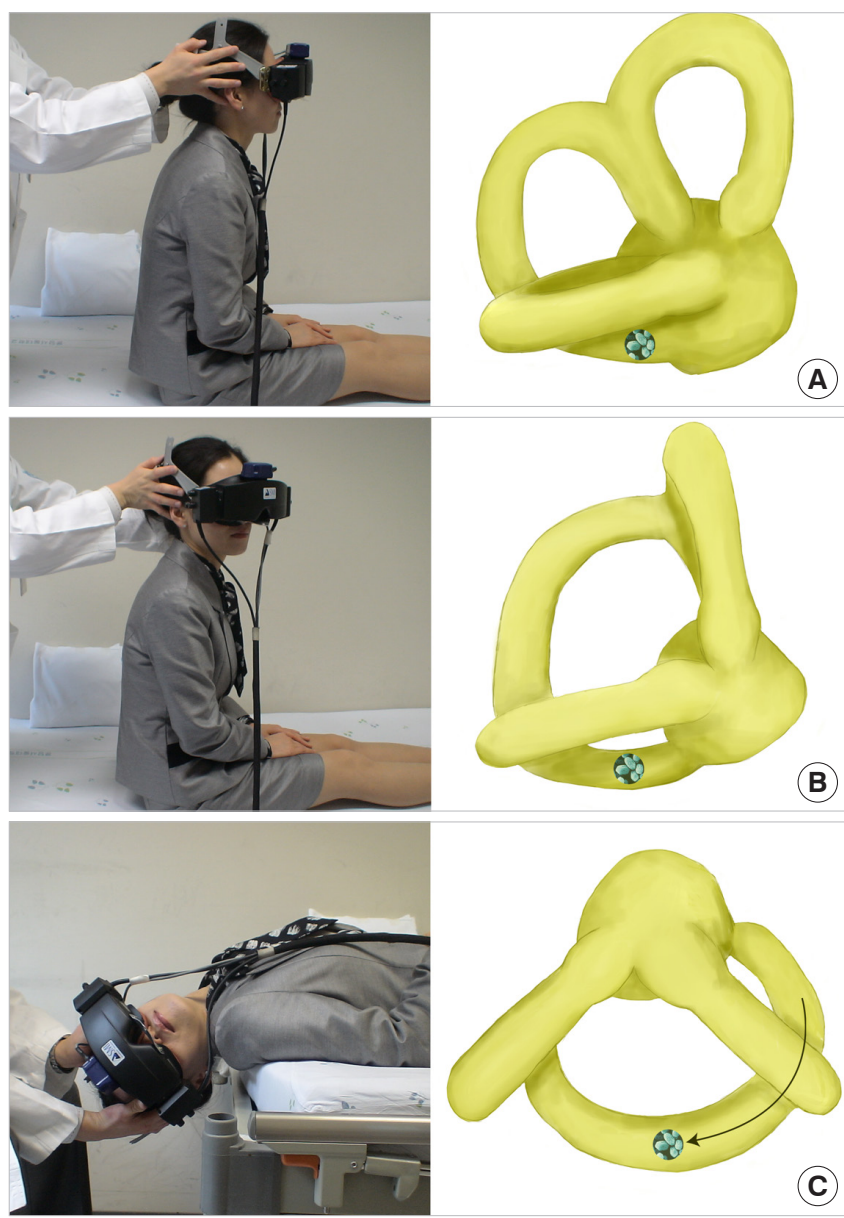

Fig. 5. The Dix-Hallpike maneuver for benign paroxysmal positional vertigo usually arises from the posterior semicircular canal. After seating the patient upright $(A)$, the head is turned $45^{\circ}$ in the direction of the involved ear ( $B$, right ear in this figure). The patient is then moved from the sitting to supine position, ending with the head hanging at $20^{\circ}$ off the end of the examination table (C). The corresponding illustrations demonstrate the orientation of the semicircular canals and location of the otolithic debris in the posterior semicircular canal (viewed from the patient's right side). 
teoporosis ${ }^{74}$ and decreased serum levels of vitamin D. ${ }^{75}$

BPPV is the most common cause of vertigo and treated easily at the bedside. ${ }^{76}$ Understanding the diagnostic maneuvers and canalith repositioning therapy for each type of BPPV is very important for correct diagnosis and proper treatment (Table 3).

\section{PC-BPPV}

In PC-BPPV, paroxysmal vertigo and nystagmus are typically induced by the Dix-Hallpike maneuver (Fig. 5). During this maneuver, otolithic debris in the ipsilateral posterior canal move away from the cupula (canalolithiasis), and the induced ampullofugal
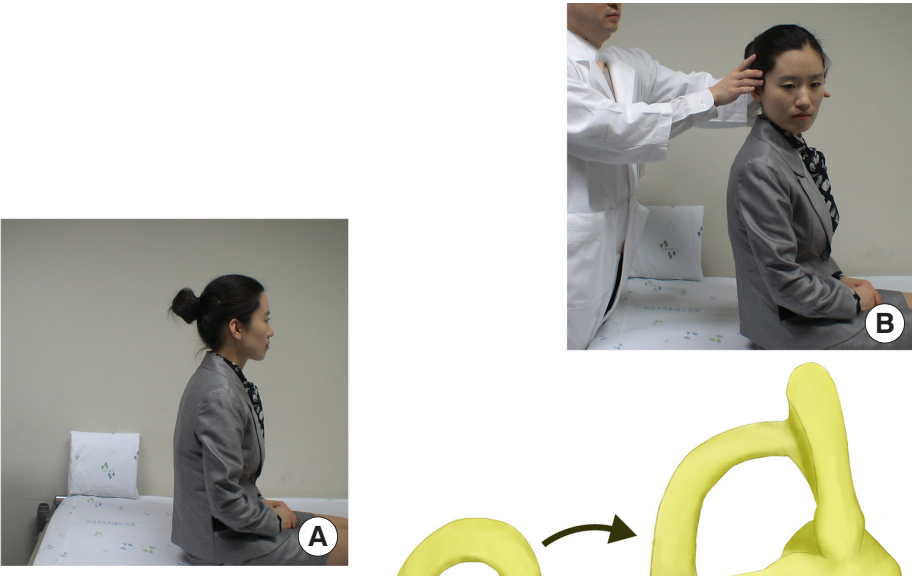

\section{(3)}
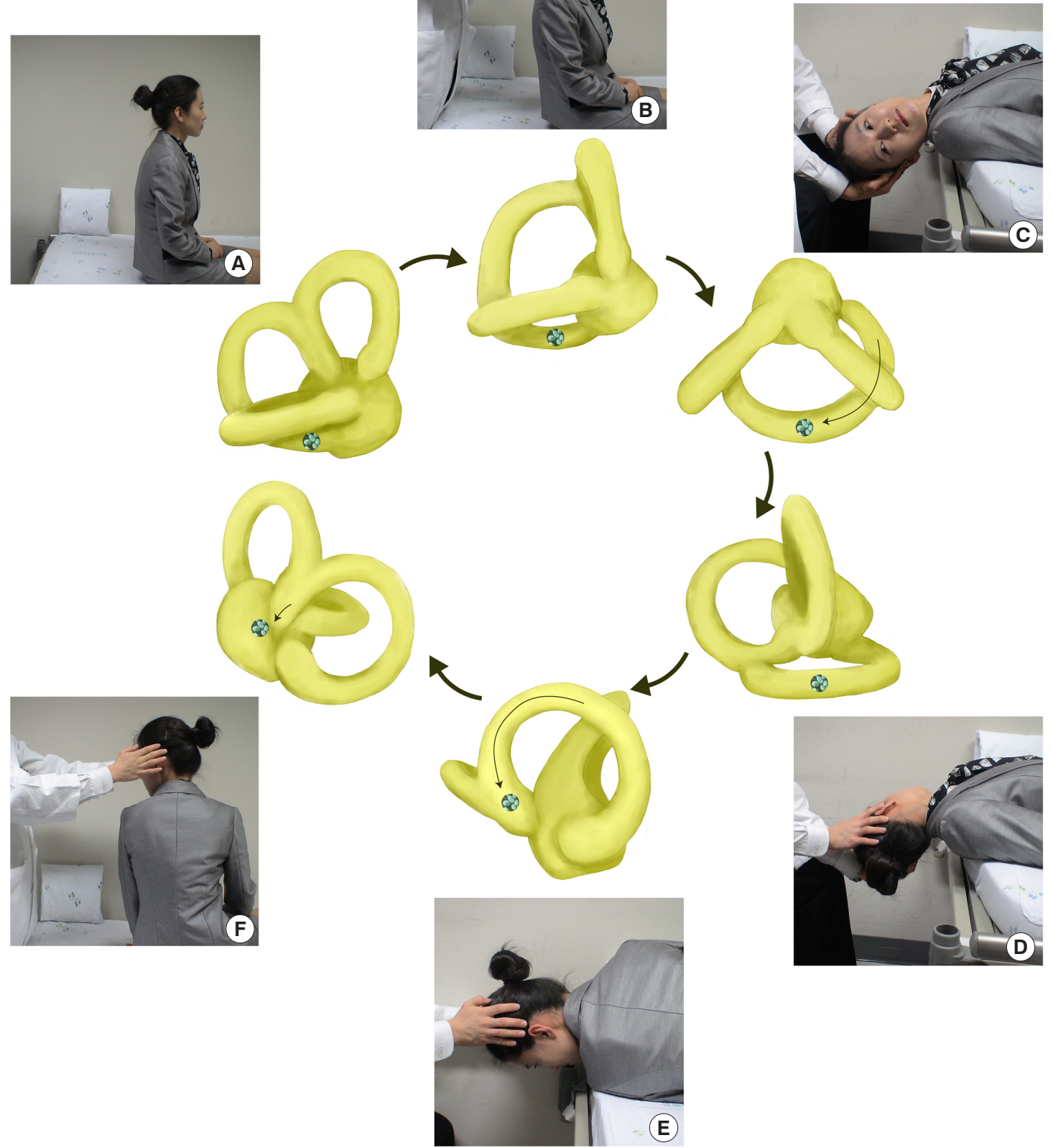

Fig. 6. Epley maneuver for right benign paroxysmal positional vertigo arising from the posterior semicircular canal. The initial steps (A-C) are the same as the Dix-Hallpike maneuver in Fig. 5. The physician turns the patient's head $90^{\circ}$ to the left (D). The physician then turns the patient's head an additional $90^{\circ}$ to the left while the patient rotates his or her body $90^{\circ}$ in the same direction (E). The patient then sits up on the left side of the examination table (F). Each position should be maintained for at least 30 seconds, until the induced nystagmus subsides. Informed consent was received from the patient. 
(away from the cupula) endolymph flow stimulates the posterior canal. From this stimulation, upbeating and ipsiversive torsional nystagmus (top poles of the eyes beating toward the downward ear) is evoked. This nystagmus usually occurs after a brief latency ( 2 to 5 seconds) and resolves within 1 minute. ${ }^{69}$ When the patient is moved from the recumbent to sitting position, the direction of nystagmus is reversed (i.e., downbeat and contraversive torsional). This nystagmus decreases with repeated maneuvers (fatigue phenomenon). ${ }^{73}$

The Epley maneuver, developed to treat PC-BPPV, consists of stepwise $90^{\circ}$ rotations of the head toward the unaffected side. ${ }^{77}$ The Epley maneuver is performed in five steps, including two from the Dix-Hallpike maneuver. After the Dix-Hallpike maneuver, the head is turned $90^{\circ}$ towards the healthy side. The induced nystagmus, if present during this step, would be in the same direction as the one evoked during the Dix-Hallpike maneuver. The head is then turned another $90^{\circ}$, to a facedown position, and the trunk is turned $90^{\circ}$ in the same direction, with the patient lying on the unaffected side. The patient is then moved to the sitting position. Otoconia move around the canal with each step of this maneuver and eventually drop out into the vestibule. Each position should be maintained until the induced nystagmus or vertigo dissipates, but always for at least 30 seconds (Fig. 6).

The Semont maneuver is an alternative to the Epley maneuver for treating PC-BPPV, especially for patients with back pain. ${ }^{78}$ During this maneuver, the patient makes a quick sweeping movement from the affected to the unaffected side (Fig. 7). Since this movement should be done rapidly (ideally within 1.3 seconds $^{79}$ ), applying the Semont maneuver can be difficult for older or obese patients.

\section{HC-BPPV}

HC-BPPV is characterized by paroxysmal vertigo and directionchanging nystagmus beating towards the lowermost (geotropic) or uppermost (apogeotropic) ear during head turning to either side
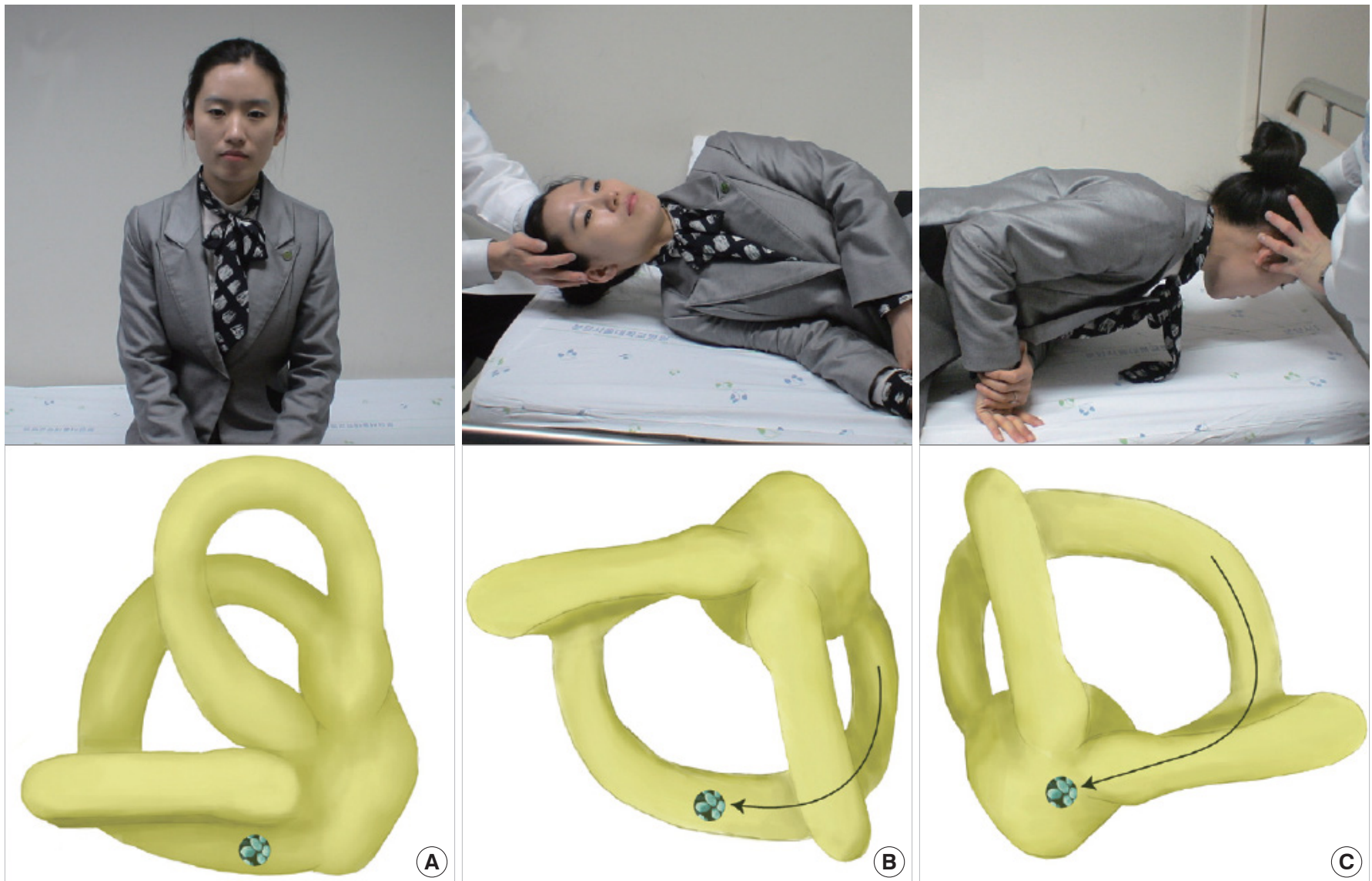

Fig. 7. The Semont maneuver for treatment of right benign paroxysmal positional vertigo arising from the posterior semicircular canal. While sitting up (A), the patient's head is turned $45^{\circ}$ to the unaffected side (left side), and then patient is rapidly moved into a side-lying position on the affected side ( $B$, right side). This position is held for about 30 seconds, then the patient is rapidly taken to the opposite side-lying position without pausing (C). The patient holds this position for about 1 minute and then moves to a sitting position. Informed consent was received from the patient. 
while supine (head-rolling test). ${ }^{80}$ The geotropic type of HC-BPPV has been ascribed to free-floating otolithic debris in the horizontal canal (canalolithiasis), and the apogeotropic type has been attributed to debris attached to the cupula (cupulopithiasis) or in the anterior arm of the canal. ${ }^{77}$
For HC-BPPV diagnosis, the patient is quickly taken from the sitting to supine position with the head lifted $30^{\circ}$ on a pillow, to bring the $\mathrm{HC}$ into the vertical plane. In this position, lying down nystagmus is observed. Thereafter, a quick $90^{\circ}$ lateral head rotation to one side is delivered while the patient remains supine. Then
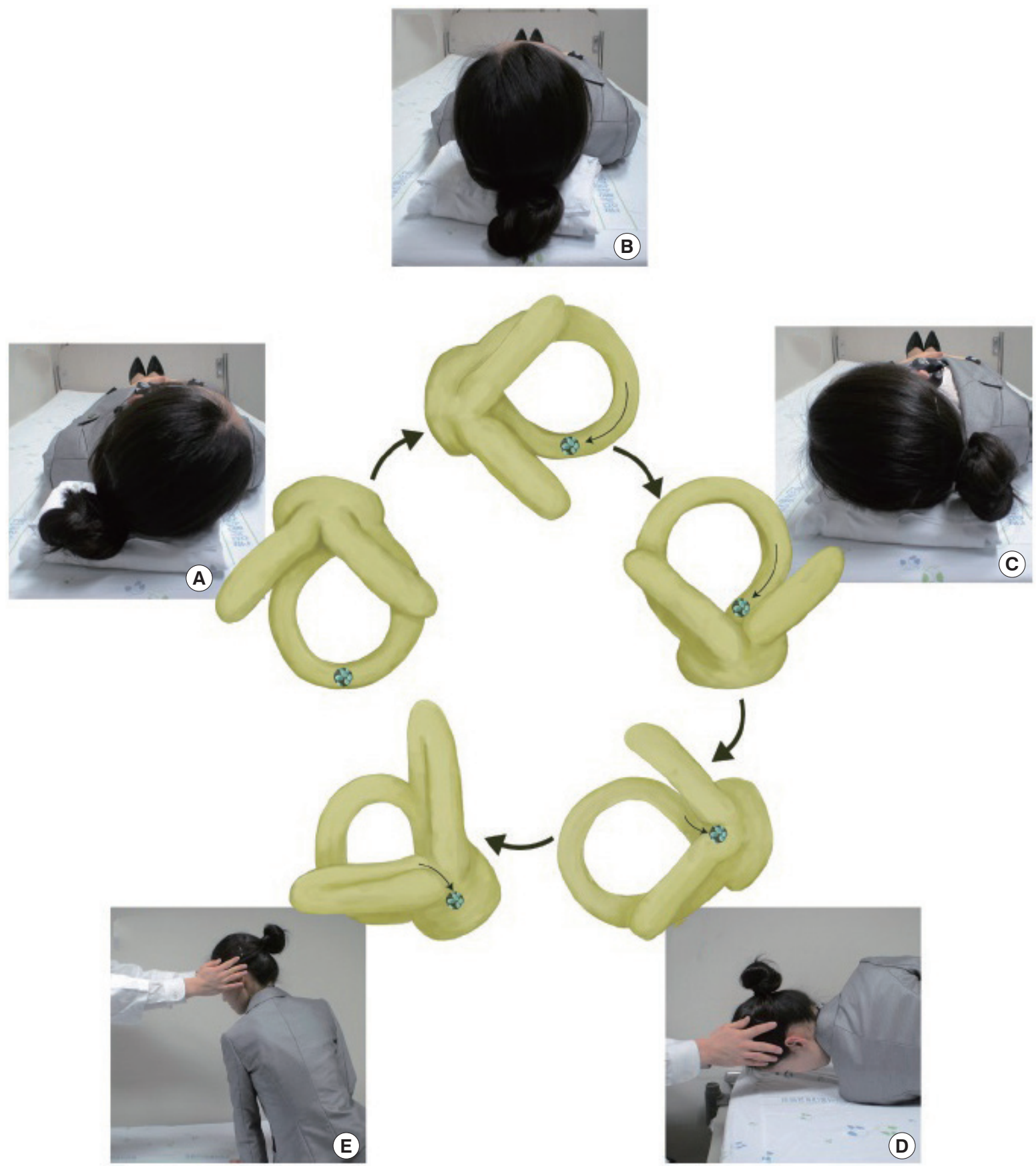

Fig. 8. Barbecue maneuver for the treatment of geotropic benign paroxysmal positional vertigo involving the right horizontal semicircular canal (HC). After turning the head to the right ( $\mathrm{A}$, involved side), the head is turned $270^{\circ}$ toward the unaffected side through a series of stepwise $90^{\circ}$ turns (B-D) before resuming the sitting position (E). The free-floating otolithic debris in the right $\mathrm{HC}$ would move away from the ampulla, and then enter the utricle. During each step of the repositioning maneuver, the induced nystagmus should beat to the left for proper migration of the otolithic debris. Each position should be maintained for 30 seconds to 1 minute, or until the induced nystagmus and vertigo resolve. 

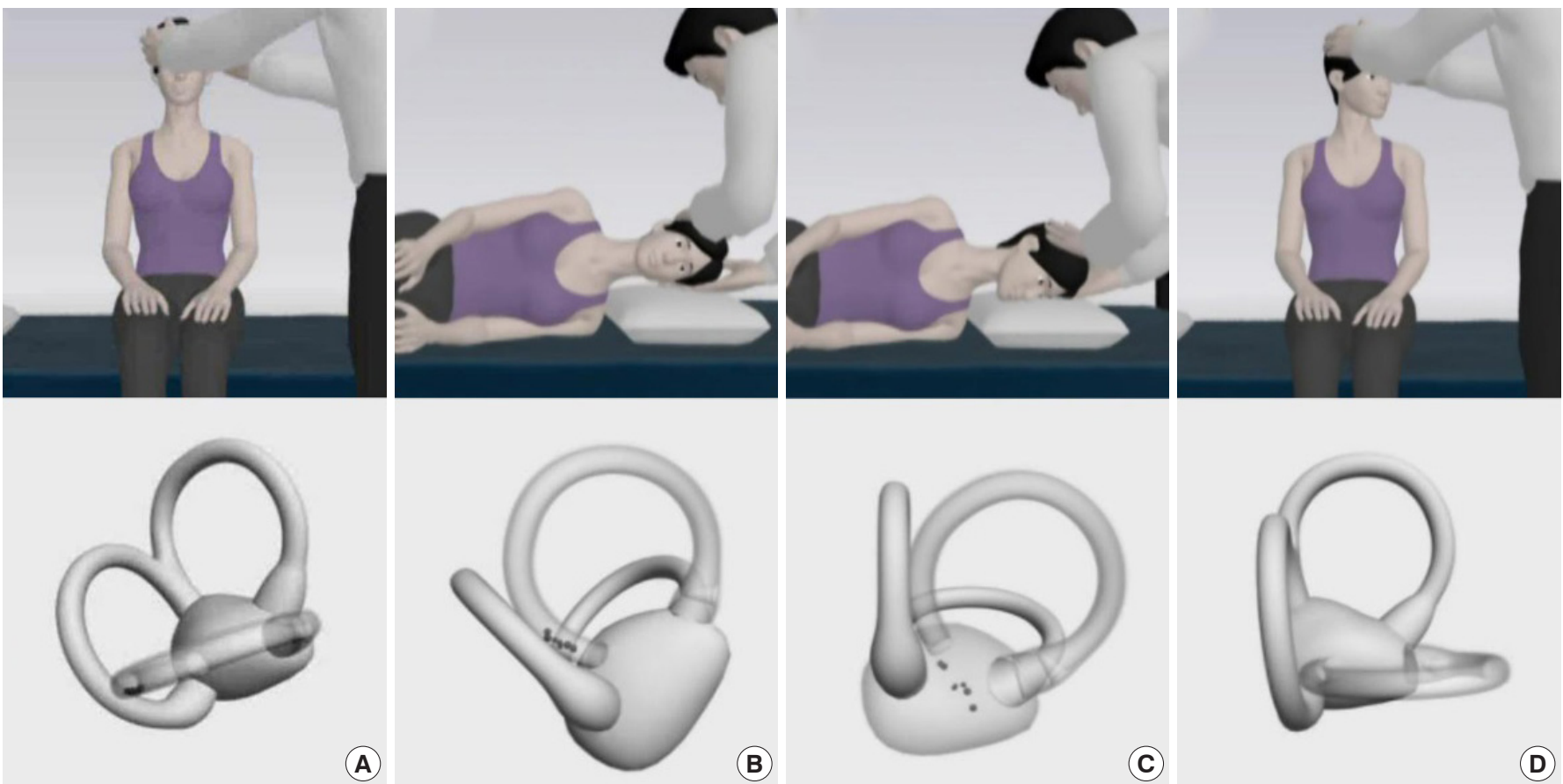

(B)

(C)

Fig. 9. Gufoni maneuver for the treatment of geotropic benign paroxysmal positional vertigo involving the right horizontal semicircular canal (HC). From the sitting position (A), the patient lies onto the healthy left side (B). In the sitting position, the otolithic debris are located in the dependent posterior arm of right $\mathrm{HC}(\mathrm{A})$. Side-lying to the healthy side causes the particles to move further toward the posterior part of the right $\mathrm{HC}$ (B) and this migration produces an ampullofugal endolymph flow and nystagmus beating to the ground due to inhibition of the right $\mathrm{HC}$. In the side-lying position, the head is rotated toward the ground (C). With this positional change, the particles move further toward the posterior part and fall into the utricle, causing ampullofugal endolymph flow and nystagmus beating to the healthy left side (C). The patient is then returned to the upright position (D). Each position is maintained for 2 minutes.

the head is turned to the other side, keeping the head flexed at $30^{\circ}$. The geotropic type of HC-BPPV is diagnosed by horizontal direction-changing nystagmus beating toward the lowermost ear on head turning to either side. Geotropic nystagmus usually has a latency of several seconds, rapidly builds up, and usually dissipates within 1 minute. In contrast, apogeotropic nystagmus beats toward the uppermost ear with a maximum intensity immediately after positioning, and may last more than 1 minute. ${ }^{81}$ In HCBPPV, the affected ear is usually identified by comparing the intensity of nystagmus in each direction. ${ }^{82}$ The assumption is that nystagmus is more intense when the head is rotated toward the affected side in the geotropic type, whereas the reverse is true for the apogeotropic type. When the induced nystagmus is symmetric, the direction of lying-down nystagmus may help lateralization. In the geotropic type, lying-down nystagmus usually beats away from the affected side, while beating towards the affected ear is seen in the apogeotropic type. ${ }^{82}$

Geotropic HC-BPPV is usually treated with barbecue $\left(360^{\circ}\right.$ roll) rotation or the Gufoni maneuver. For barbecue rotation, the patient's head is rotated $270^{\circ}$ with sequential $90^{\circ}$ turns from the affected ear down position to the prone position (Fig. 8). ${ }^{83}$ The Gu- foni maneuver for geotropic HC-BPPV involves side-lying from a sitting position with the unaffected ear down, head turning toward the floor, and resuming the sitting position (Fig. 9). ${ }^{84}$ Each position should be maintained for 1 to 2 minutes. A recent randomized trial showed that both the barbeque rotation and Gufoni maneuver are more effective than a sham maneuver (success rates of $68 \%, 61 \%$, and $35 \%$, respectively). ${ }^{85}$ Treatment of apogeotropic HC-BPPV involves maneuvers designed to detach the otolithic debris from the cupula, or to move the debris from the anterior arm of the $\mathrm{HC}$ to the posterior arm. ${ }^{86}$ Horizontal head shaking for 15 seconds and the Gufoni maneuver are usually adopted for this purpose. ${ }^{87}$ During the Gufoni maneuver, designed to treat apogeotropic HC-BPPV, the patient sits upright, looking straight head, and then quickly lies down on the affected side. They remain in this position for 1 to 2 minutes after the nystagmus has stopped or markedly reduces. The head is then quickly turned $45^{\circ}$ toward the ceiling and held in this position for 2 minutes, after which the patient slowly resumes the sitting position (Fig. 10). A randomized trial showed significantly higher rates of immediate symptom resolution with the head shaking and Gufoni maneuvers compared to a sham maneuver $\left(62 \%, 73 \%\right.$, and $35 \%$, respectively). ${ }^{87}$ 

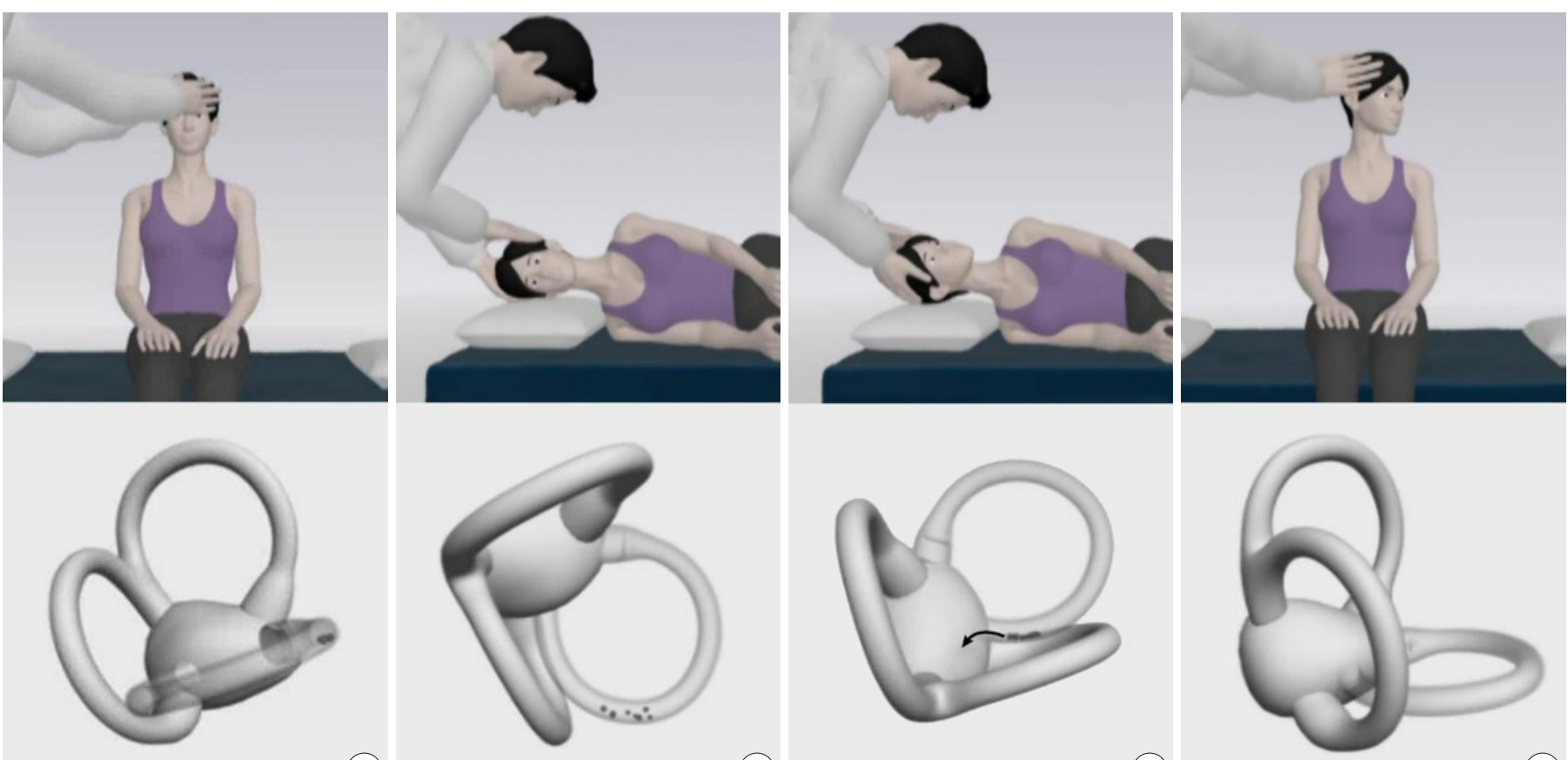

(A)

(B)
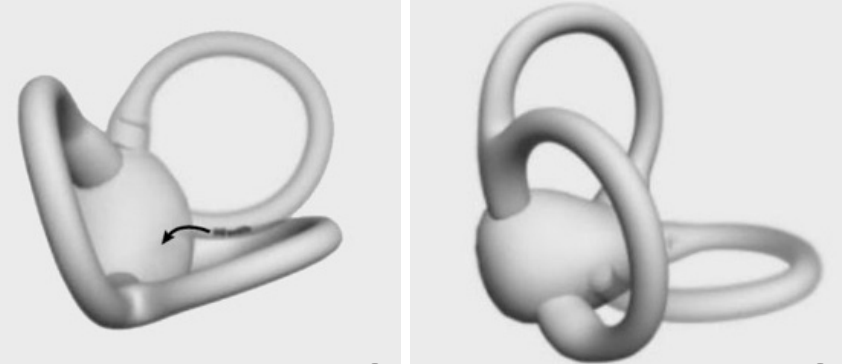

(C)

Fig. 10. Gufoni maneuver for treatment of apogeotropic benign paroxysmal positional vertigo involving the right horizontal semicircular canal (HC). From the sitting position (A), the patient lies onto the affected right side (B). In the sitting position, the otolithic debris are attached to the cupula or located in the anterior part of the right $\mathrm{HC}(\mathrm{A})$. Side-lying to the right side causes the particles to move toward the posterior part of the $\mathrm{HC}$ and this migration produces an ampullofugal endolymph flow and nystagmus beating away from the ground (B). In the side-lying position, the head is rotated toward the ceiling (C). With this head turning, the particles move further toward the posterior and fall into the utricle, causing an ampullofugal endolymph flow and nystagmus beating to the healthy side due to inhibition of right $\mathrm{HC}$ (C). Finally, the patient resumes the upright position (D). Each position is maintained for 2 minutes.

\section{CONCLUSION AND RECOMMENDATIONS}

The evaluation and proper management of acute dizziness/vertigo are very important in the ED. Particular attention should be paid to potentially life-threatening disorders as a cause of acute dizziness/vertigo. A recently proposed approach to dizziness/vertigo begins with classifying the type of dizziness/vertigo presentation. Physicians in the ED should be familiar with examinations to detect central vestibular signs, such as negative HIT, directionchanging nystagmus, and skew deviation, in patients with acute prolonged spontaneous dizziness/vertigo. These signs are more sensitive than brain imaging in detecting stroke presenting with acute isolated dizziness/vertigo. Isolated positional vertigo is almost always caused by BPPV, which can be readily treated with canalith repositioning maneuvers once the involved semicircular canal is determined. Over the past decades, we have achieved marked progress in the evaluation and management of acute dizziness/vertigo. Even with the splendid developments in imaging technology, the diagnosis of acute dizziness/vertigo largely remains the realm of bedside examination.

\section{CONFLICT OF INTEREST}

No potential conflict of interest relevant to this article was reported.

\section{REFERENCES}

1. Cappello M, di Blasi U, di Piazza L, et al. Dizziness and vertigo in a department of emergency medicine. Eur J Emerg Med 1995;2:201-11.

2. Baloh RW. Vertigo. Lancet 1998;352:1841-6.

3. Newman-Toker DE, Cannon LM, Stofferahn ME, Rothman RE, Hsieh YH, Zee DS. Imprecision in patient reports of dizziness symptom quality: a cross-sectional study conducted in an acute care setting. Mayo Clin Proc 2007;82:1329-40.

4. Drachman DA, Hart CW. An approach to the dizzy patient. Neurology 1972;22:323-34.

5. Hanley K, O' Dowd T. Symptoms of vertigo in general practice: a prospective study of diagnosis. Br J Gen Pract 2002;52:80912.

6. Choi JH, Seo JD, Kim MJ, et al. Vertigo and nystagmus in orthostatic hypotension. Eur J Neurol 2015;22:648-55. 
7. Kim SH, Park SH, Kim HJ, Kim JS. Isolated central vestibular syndrome. Ann N Y Acad Sci 2015;1343:80-9.

8. Savitz SI, Caplan LR. Vertebrobasilar disease. N Engl J Med 2005;352:2618-26.

9. Paul NL, Simoni M, Rothwell PM; Oxford Vascular Study. Transient isolated brainstem symptoms preceding posterior circulation stroke: a population-based study. Lancet Neurol 2013; 12:65-71.

10. Searls DE, Pazdera L, Korbel E, Vysata O, Caplan LR. Symptoms and signs of posterior circulation ischemia in the new England medical center posterior circulation registry. Arch Neurol 2012;69:346-51.

11. Akhtar N, Kamran SI, Deleu D, et al. Ischaemic posterior circulation stroke in State of Qatar. Eur J Neurol 2009;16:1004-9.

12. Choi KD, Lee $H$, Kim JS. Vertigo in brainstem and cerebellar strokes. Curr Opin Neurol 2013;26:90-5.

13. Lee $\mathrm{H}$, Sohn $\mathrm{Sl}$, Cho YW, et al. Cerebellar infarction presenting isolated vertigo: frequency and vascular topographical patterns. Neurology 2006;67:1178-83.

14. Kattah JC, Talkad AV, Wang DZ, Hsieh YH, Newman-Toker DE. HINTS to diagnose stroke in the acute vestibular syndrome: three-step bedside oculomotor examination more sensitive than early MRI diffusion-weighted imaging. Stroke 2009;40: 3504-10.

15. Newman-Toker DE, Saber Tehrani AS, Mantokoudis G, et al. Quantitative video-oculography to help diagnose stroke in acute vertigo and dizziness: toward an ECG for the eyes. Stroke 2013:44:1158-61.

16. Saber Tehrani AS, Kattah JC, Mantokoudis G, et al. Small strokes causing severe vertigo: frequency of false-negative MRIs and nonlacunar mechanisms. Neurology 2014;83:169-73.

17. Baloh RW. Differentiating between peripheral and central causes of vertigo. Otolaryngol Head Neck Surg 1998;119:55-9.

18. Lee CC, Su YC, Ho HC, et al. Risk of stroke in patients hospitalized for isolated vertigo: a four-year follow-up study. Stroke 2011:42:48-52.

19. Johnston SC, Rothwell PM, Nguyen-Huynh MN, et al. Validation and refinement of scores to predict very early stroke risk after transient ischaemic attack. Lancet 2007;369:283-92.

20. Navi BB, Kamel H, Shah MP, et al. Application of the ABCD2 score to identify cerebrovascular causes of dizziness in the emergency department. Stroke 2012;43:1484-9.

21. Serra A, Leigh RJ. Diagnostic value of nystagmus: spontaneous and induced ocular oscillations. J Neurol Neurosurg Psychiatry 2002;73:615-8.

22. Baloh RW. Clinical practice: vestibular neuritis. N Engl J Med 2003;348:1027-32.
23. Robinson DA, Zee DS, Hain TC, Holmes A, Rosenberg LF. Alexander's law: its behavior and origin in the human vestibuloocular reflex. Ann Neurol 1984;16:714-22.

24. Hotson JR, Baloh RW. Acute vestibular syndrome. N Engl J Med 1998;339:680-5.

25. Baloh RW, Yee RD. Spontaneous vertical nystagmus. Rev Neurol (Paris) 1989;145:527-32.

26. Bohmer A, Straumann D. Pathomechanism of mammalian downbeat nystagmus due to cerebellar lesion: a simple hypothesis. Neurosci Lett 1998;250:127-30.

27. Baloh RW, Spooner JW. Downbeat nystagmus: a type of central vestibular nystagmus. Neurology 1981;31:304-10.

28. Glasauer S, Hoshi M, Kempermann U, Eggert T, Buttner U. Threedimensional eye position and slow phase velocity in humans with downbeat nystagmus. J Neurophysiol 2003;89:338-54.

29. Huh YE, Kim JS. Bedside evaluation of dizzy patients. J Clin Neurol 2013;9:203-13.

30. Choi KD, Oh SY, Kim HJ, Koo JW, Cho BM, Kim JS. Recovery of vestibular imbalances after vestibular neuritis. Laryngoscope 2007;117:1307-12.

31. Buttner U, Grundei T. Gaze-evoked nystagmus and smooth pursuit deficits: their relationship studied in 52 patients. $J$ Neurol 1995;242:384-9.

32. Leigh RJ, Zee DS. The neurology of eye movements. 4th ed. New York: Oxford University Press; 2006.

33. Choi KD, Oh SY, Park SH, Kim JH, Koo JW, Kim JS. Head-shaking nystagmus in lateral medullary infarction: patterns and possible mechanisms. Neurology 2007;68:1337-44.

34. Hain TC, Fetter M, Zee DS. Head-shaking nystagmus in patients with unilateral peripheral vestibular lesions. Am J Otolaryngol 1987;8:36-47.

35. Minagar A, Sheremata WA, Tusa RJ. Perverted head-shaking nystagmus: a possible mechanism. Neurology 2001;57:887-9.

36. Kim JS, Ahn KW, Moon SY, Choi KD, Park SH, Koo JW. Isolated perverted head-shaking nystagmus in focal cerebellar infarction. Neurology 2005;64:575-6.

37. Huh YE, Kim JS. Patterns of spontaneous and head-shaking nystagmus in cerebellar infarction: imaging correlations. Brain 2011;134:3662-71.

38. Halmagyi GM, Curthoys IS. A clinical sign of canal paresis. Arch Neurol 1988;45:737-9.

39. Weber KP, Aw ST, Todd MJ, McGarvie LA, Curthoys IS, Halmagyi GM. Head impulse test in unilateral vestibular loss: vestibulo-ocular reflex and catch-up saccades. Neurology 2008;70: 454-63.

40. Newman-Toker DE, Kattah JC, Alvernia JE, Wang DZ. Normal head impulse test differentiates acute cerebellar strokes from 
vestibular neuritis. Neurology 2008;70:2378-85.

41. Walker MF, Zee DS. Directional abnormalities of vestibular and optokinetic responses in cerebellar disease. Ann N Y Acad Sci 1999;871:205-20.

42. Walker MF, Zee DS. Cerebellar disease alters the axis of the high-acceleration vestibuloocular reflex. J Neurophysiol 2005; 94:3417-29.

43. Jeong SH, Kim JS, Baek IC, et al. Perverted head impulse test in cerebellar ataxia. Cerebellum 2013;12:773-5.

44. Perez N, Rama-Lopez J. Head-impulse and caloric tests in patients with dizziness. Otol Neurotol 2003;24:913-7.

45. Brodsky MC, Donahue SP, Vaphiades M, Brandt T. Skew deviation revisited. Surv Ophthalmol 2006;51:105-28.

46. Smith JL, David NJ, Klintworth G. Skew deviation. Neurology 1964;14:96-105.

47. Dieterich M, Brandt T. Ocular torsion and tilt of subjective visual vertical are sensitive brainstem signs. Ann Neurol 1993; 33:292-9.

48. Chalela JA, Kidwell CS, Nentwich LM, et al. Magnetic resonance imaging and computed tomography in emergency assessment of patients with suspected acute stroke: a prospective comparison. Lancet 2007;369:293-8.

49. Oppenheim C, Stanescu R, Dormont D, et al. False-negative diffusion-weighted MR findings in acute ischemic stroke. AJNR Am J Neuroradiol 2000;21:1434-40.

50. Tarnutzer AA, Berkowitz AL, Robinson KA, Hsieh YH, NewmanToker DE. Does my dizzy patient have a stroke? A systematic review of bedside diagnosis in acute vestibular syndrome. CMAJ 2011;183:E571-92.

51. Kim JS, Cho KH, Lee H. Isolated labyrinthine infarction as a harbinger of anterior inferior cerebellar artery territory infarction with normal diffusion-weighted brain MRI. J Neurol Sci 2009 15;278:82-4.

52. Kim DU, Han MK, Kim JS. Isolated recurrent vertigo from stenotic posterior inferior cerebellar artery. Otol Neurotol 2011; 32:180-2.

53. Huh YE, Koo JW, Lee H, Kim JS. Head-shaking aids in the diagnosis of acute audiovestibular loss due to anterior inferior cerebellar artery infarction. Audiol Neurootol 2013;18:11424.

54. Choi SY, Kee HJ, Park JH, Kim HJ, Kim JS. Combined peripheral and central vestibulopathy. J Vestib Res 2014;24:443-51.

55. Grad A, Baloh RW. Vertigo of vascular origin: clinical and electronystagmographic features in 84 cases. Arch Neurol 1989; 46:281-4.

56. Hoshino T, Nagao T, Mizuno S, Shimizu S, Uchiyama S. Transient neurological attack before vertebrobasilar stroke. J Neu- rol Sci 2013;325:39-42.

57. Fisher CM. Vertigo in cerebrovascular disease. Arch Otolaryngol 1967;85:529-34.

58. Lee $\mathrm{H}, \mathrm{Cho}$ YW. Auditory disturbance as a prodrome of anterior inferior cerebellar artery infarction. J Neurol Neurosurg Psychiatry 2003;74:1644-8.

59. Kim JS, Lopez I, DiPatre PL, Liu F, Ishiyama A, Baloh RW. Internal auditory artery infarction: clinicopathologic correlation. Neurology 1999;52:40-4.

60. Lee $\mathrm{H}$. Audiovestibular loss in anterior inferior cerebellar artery territory infarction: a window to early detection? J Neurol Sci 2012;313:153-9.

61. Kim HA, Lee SR, Lee $H$. Acute peripheral vestibular syndrome of a vascular cause. J Neurol Sci 2007;254:99-101.

62. Kim JS, Lee H. Vertigo due to posterior circulation stroke. Semin Neurol 2013;33:179-84.

63. Jackson $C$, Sudlow C. Comparing risks of death and recurrent vascular events between lacunar and non-lacunar infarction. Brain 2005;128:2507-17.

64. Jeong SH, Kim HJ, Kim JS. Vestibular neuritis. Semin Neurol 2013;33:185-94.

65. Fishman JM, Burgess C, Waddell A. Corticosteroids for the treatment of idiopathic acute vestibular dysfunction (vestibular neuritis). Cochrane Database Syst Rev 2011:CD008607.

66. Strupp M, Zingler VC, Arbusow V, et al. Methylprednisolone, valacyclovir, or the combination for vestibular neuritis. N Engl J Med 2004;351:354-61.

67. Strupp M, Arbusow V, Maag KP, Gall C, Brandt T. Vestibular exercises improve central vestibulospinal compensation after vestibular neuritis. Neurology 1998;51:838-44.

68. Bisdorff A, Von Brevern M, Lempert T, Newman-Toker DE. Classification of vestibular symptoms: towards an international classification of vestibular disorders. J Vestib Res 2009;19:113.

69. Kim JS, Zee DS. Clinical practice. Benign paroxysmal positional vertigo. N Engl J Med 2014;370:1138-47.

70. Epley JM. The canalith repositioning procedure: for treatment of benign paroxysmal positional vertigo. Otolaryngol Head Neck Surg 1992;107:399-404.

71. Shim DB, Ko KM, Lee JH, Park HJ, Song MH. Natural history of horizontal canal benign paroxysmal positional vertigo is truly short. J Neurol 2015;262:74-80.

72. Cambi J, Astore S, Mandala M, Trabalzini F, Nuti D. Natural course of positional down-beating nystagmus of peripheral origin. J Neurol 2013;260:1489-96.

73. Baloh RW, Honrubia V, Jacobson K. Benign positional vertigo: clinical and oculographic features in 240 cases. Neurology 
1987;37:371-8.

74. Jeong SH, Choi SH, Kim JY, Koo JW, Kim HJ, Kim JS. Osteopenia and osteoporosis in idiopathic benign positional vertigo. Neurology 2009;72:1069-76.

75. Jeong SH, Kim JS, Shin JW, et al. Decreased serum vitamin D in idiopathic benign paroxysmal positional vertigo. J Neurol 2013;260:832-8.

76. Fife TD, Iverson DJ, Lempert T, et al. Practice parameter: therapies for benign paroxysmal positional vertigo (an evidencebased review). Report of the Quality Standards Subcommittee of the American Academy of Neurology. Neurology 2008;70: 2067-74.

77. Parnes LS, McClure JA. Free-floating endolymph particles: a new operative finding during posterior semicircular canal occlusion. Laryngoscope 1992;102:988-92.

78. Semont A, Freyss G, Vitte E. Curing the BPPV with a liberatory maneuver. Adv Otorhinolaryngol 1988;42:290-3.

79. Faldon ME, Bronstein AM. Head accelerations during particle repositioning manoeuvres. Audiol Neurootol 2008;13:345-56.

80. Brandt T. Benign paroxysmal positioning vertigo. Adv Otorhinolaryngol 1999;55:169-94.

81. Sekine K, Imai T, Nakamae K, Miura K, Fujioka H, Takeda N.
Dynamics of the vestibulo-ocular reflex in patients with the horizontal semicircular canal variant of benign paroxysmal positional vertigo. Acta Otolaryngol 2004;124:587-94.

82. Han $\mathrm{Bl}, \mathrm{Oh} \mathrm{HJ}$, Kim JS. Nystagmus while recumbent in horizontal canal benign paroxysmal positional vertigo. Neurology 2006;66:706-10.

83. Lempert T. Horizontal benign positional vertigo. Neurology 1994:44:2213-4.

84. Korres S, Riga MG, Xenellis J, Korres GS, Danielides V. Treatment of the horizontal semicircular canal canalithiasis: pros and cons of the repositioning maneuvers in a clinical study and critical review of the literature. Otol Neurotol 2011;32: 1302-8.

85. Kim JS, Oh SY, Lee SH, et al. Randomized clinical trial for geotropic horizontal canal benign paroxysmal positional vertigo. Neurology 2012;79:700-7.

86. Nuti D, Mandala M, Salerni L. Lateral canal paroxysmal positional vertigo revisited. Ann N Y Acad Sci 2009;1164:316-23.

87. Kim JS, Oh SY, Lee $S H$, et al. Randomized clinical trial for apogeotropic horizontal canal benign paroxysmal positional vertigo. Neurology 2012;78:159-66. 